\title{
Bornean Orangutans (Pongo pygmaeus pygmaeus) Use Water as a Tool in the Floating Object Task
}

\author{
Caroline M. DeLong* and Christina Burnett
}

Department of Psychology, Rochester Institute of Technology

*Corresponding author (Email: cmdgsh@ rit.edu)

Citation - DeLong, C. M., \& Burnett, C. (2020). Bornean orangutans (Pongo pygmaeus pygmaeus) use water as a tool in the floating object task. Animal Behavior and Cognition, 7(3), 327-342.

doi:https://doi.org/10.26451/abc.07.03.05.2020

\begin{abstract}
The purpose of this study was to investigate Bornean orangutans' ability to use water as a tool. In the floating object task, subjects must spit water into a vertical transparent tube to obtain an out-of-reach food reward (peanut). Two zoo-living orangutans were tested: Denda, a 13-year-old male, and Kumang, a 38-year-old female. Three conditions were presented: 'wet', in which the tube was quarter-filled with water; 'dry - stick tools', in which the tube had no water and six stick tools that were unnecessary for obtaining the reward were provided; and 'dry', in which the tube had no water and no stick tools were provided. Both subjects completed two sessions in each condition. The dry conditions were presented first because it is a cognitively more demanding task to use water to obtain the peanut when there is no water in the tube initially to provide a cue. Denda was successful in all six sessions while Kumang was successful in only three sessions. Both subjects' latency to spit water into the tube decreased exponentially across sessions. Both individuals displayed a variety of strategies to solve the problem, including using and manufacturing tools utilizing objects in their enclosure. Denda is the first orangutan to succeed on the task when presented with the 'dry' condition first. This study provides the first evidence of Bornean orangutans spontaneously solving the floating object task, but the mechanism underlying their success remains unclear.
\end{abstract}

Keywords - Floating object task, Orangutans, Problem solving, Tool use

Many nonhuman animals have been shown to use tools (Sanz et al., 2013; Seed \& Bryne, 2010). In the past, tools were characterized as primarily discrete rigid objects used to attain a goal (Beck, 1980). Shumaker et al.'s (2011) updated definition of tool use is:

the external employment of an unattached or manipulable attached environmental object to alter more efficiently the form, position, or condition of another object, another organism, or the user itself, when the user holds and directly manipulates the tool during or prior to use and is responsible for the proper and effective orientation of the tool. (p. 10)

St. Amant and Horton (2008) have offered their own definition:

the exertion of control over a freely manipulable external object (the tool) with the goal of (1) altering the physical properties of another object, substance, surface, or medium (the target, which may be the tool user or another organism) via a dynamic mechanical interaction, or (2) mediating the flow of information between the tool user and the environment or other organisms in the environment. (p. 103)

Thus, tools do not need to be rigid objects, and conspecifics can even be considered "social tools" (Völter et al., 2015). Aquatic animal species, such as stingrays and archerfish, can manipulate water in 
order to accomplish a desired goal, and many agree that this is also considered tool use (Alcock, 1972; Bshary et al., 2002; Kuba et al., 2010; Schuster et al., 2004). Kuba et al.'s (2010) definition of tool use is "an action involving an agent to achieve a goal" (p. 508). By this definition, water can be considered an agent, and thus a tool.

Mendes and colleagues (2007) developed the "floating peanut task" (also called the floating object task) to investigate the use of water as a tool in nonhuman primates. In this task, the animal must add water to a transparent vertical tube to obtain an out-of-reach reward. Mendes et al. (2007) found that all five captive female Sumatran orangutans (Pongo abelii) they tested were able to solve the problem in the first trial. Hanus and colleagues (2011) tested other captive populations of gorillas (Gorilla gorilla), chimpanzees (Pan troglodytes), and Bornean orangutans (Pongo pygmaeus) and found that none of the gorillas or Bornean orangutans successfully retrieved the peanut. None of the 19 chimpanzees from the Leipzig Zoo solved the task in Experiment 1, and five of 24 sanctuary-housed chimpanzees (21\%) solved the task in Experiment 2. In Experiment 3, when a new water dispenser was installed, two out of 19 Leipzig Zoo chimpanzees (11\%) solved the task. Hanus et al. (2011) suggested that functional fixedness prevented the chimpanzees from obtaining water to solve the task from the old water dispenser. Tennie and colleagues (2010) found that 31 chimpanzees were unable or unmotivated to solve the floating object task independently, but eight animals (30\%) succeeded on the task after observing either a conspecific spit water into the tube or a human model pour water into the tube. Tennie et al. (2010) concluded that the observational learning, specifically emulation, increased the success of the chimpanzees. Ebel et al. (2019) found that none of the 24 sanctuary-living chimpanzees in Experiment 1 solved the task with an opaque tube, although one chimpanzee solved the task after viewing a water-filled tube with a peanut floating on top (end-state condition). In Experiment 2, five out of 18 zoo-living chimpanzees (28\%, 13 of 18 had failed to solve the task in a previous study) and none of the six bonobos they tested solved the floating object task (Ebel et al., 2019). In Experiment 3, six of eight chimpanzees and four of five Sumatran orangutans that previously succeeded on the task solved it in a re-test (Ebel et al., 2019). Seven brown capuchin monkeys presented with the floating object task were unable to spontaneously solve the task, but after viewing a human model pour water into the tube, one monkey obtained the reward using a wad of straw instead of water (Renner et al., 2017). The typically low spontaneous solution rates in these studies (except for Mendes et al., 2007) suggest that the floating object task is difficult for nonhuman primates.

The success of human children presented with the same floating object task is dependent on age, presence of water in the tube, and opportunity for observational learning. Hanus et al. (2011) found that $8 \%$ of 4 -year-olds, $42 \%$ of 6 -year-olds, and $58 \%$ of 8 -year-olds solved the task on their own. Participants in the 'wet' condition with the tube already one-quarter filled with water were more successful than participants in the 'dry' condition with no water in the tube at the start of the task, which suggests that seeing the peanut floating in water upon encountering the tube facilitated the task. Nielsen (2013) found that $100 \%$ of adults and $14 \%$ of 4 -year-olds spontaneously solved the task, and after observing an adult pour water into the tube, $61 \%$ of 4 -year-olds succeeded on the task. Like nonhuman primates, children under age eight show a low success rate without the benefit of observational learning.

The floating object task is a version of the Aesop's Fable paradigm, in which individuals drop objects into a tube of water to obtain a floating out-of-reach reward (Jelbert et al., 2015). In this case, the objects (e.g., stones) dropped into the tube are the tools (instead of the water as the tool). In these studies based on Aesop's Fable, the individuals are typically trained to drop objects into a tube to obtain a reward, and then tested with different objects, tubes, or substrates to investigate causal reasoning and physical cognition. The Aesop's Fable paradigm has been conducted with birds, including rooks (Corvus frugilegus), Western scrub jays (Aphelocoma californica), Eurasian jays (Garrulus glandarius), New Caledonian crows (Corvus moneduloides), and Great-tailed grackles (Quiscalus mexicanus; Bird \& Emery, 2009; Cheke et al., 2011; Jelbert et al., 2014; Logan, 2016; Logan et al., 2016). Birds typically learn to drop stones in the tube and some individuals show recognition for the functional properties of the task (Jelbert et al., 2015). Human children trained to drop stones into an apparatus to retrieve a reward can learn to solve water displacement tasks over several trials at age 5-7 years, but solve the tasks on the first 
trial by age 8-10 years (Cheke et al., 2012; Miller et al., 2017). Thus, both with the Aesop's Fable task and the floating object task, children show spontaneous successful solutions (without training or observational learning) at about 8 years of age.

Two non-avian species have been tested in Aesop's Fable tasks. Two out of eight raccoons (Procyon lotor) learned to drop stones in the tube to obtain a reward, but neither showed a preference for functional vs. nonfunctional stones or sinking vs. floating balls (Stanton et al., 2017). Two North American river otters (Lontra candensis), two Asian small-clawed otters (Aonyx cinereus), and two giant river otters (Pteronura brasiliensis) were tested in a combination Aesop's Fable/floating object task in which they were provided with stones, sticks, and water to raise the water level of a tube to reach a floating reward (Gormley, 2015). None of the otters successfully completed the task.

The goal of the current study was to investigate the performance of two Bornean orangutans $(P$. pygmaeus) residing at a zoo on the floating object task. Mendes et al. (2007) found that all five captive Sumatran orangutans ( $P$. abelii) they tested solved the problem on the first trial and every trial thereafter. Surprisingly, when a group of 10 sanctuary-housed Bornean orangutans ( $P$. pygmaeus) was tested, only two individuals spat water into the tube but none of the animals retrieved the reward and solved the task (Hanus et al., 2011). Given these conflicting results, we wanted to test other zoo-living Bornean orangutans: Denda, a 13-year-old male, and Kumang, a 38-year-old female. Differences in performance between individual orangutans may be due to environmental and experiential factors, such as exposure to items available in the environment that can be used as tools and prior experience with other tool-using tasks. Our subjects had participated in previous tasks using stick tools and frequently had manipulable objects in their enclosure.

We presented the task in three conditions: 'wet', in which the tube was quarter-filled with water; 'dry - stick tools', in which the tube had no water and six stick tools that were unnecessary for obtaining the reward were provided; and 'dry', in which the tube had no water and no stick tools were provided. The 'wet' and 'dry' conditions were presented in Mendes et al. (2007) and Hanus et al. (2011). The 'dry stick tools' condition was included here to explore whether our subjects would become fixated on the stick tools that they used in previous tasks with upright puzzle boxes (Keller \& DeLong, 2016; O'Leary $\&$ DeLong, 2016) and fail to use water to solve the task in that condition. Mendes et al. (2007) presented the 'wet' condition first. Unlike in Mendes et al. (2007), we presented the dry conditions first because it is a cognitively more demanding task to use water to obtain the peanut when there is no water in the tube initially to provide a cue. In the 'dry' condition, the subject must produce a solution without seeing the tool (water inside a drinker), and subjects had to recall a location where that tool could be obtained (Mendes et al., 2007). Hanus et al. (2011) presented both the wet and dry conditions, but to different individual orangutans.

There was one other difference between the current study and previous studies (Ebel et al., 2019; Hanus et al., 2011; Mendes et al., 2007; Tennie et al., 2010) in that other objects were present in the animal's enclosure that could potentially be used to attempt to solve the task, such as hay, cloth, or cardboard in this study. We were interested to see whether the individuals in our study would use or manufacture tools other than the stick tools we provided or the water in their water dispensers to attempt to solve the task. In the wild, orangutans would have many objects at their disposal to solve a problem. Orangutans create and use tools in the wild for foraging tasks (e.g., Galdikas, 1982; van Schaik et al., 1996; van Schaik \& Knott, 2001). Captive orangutans have demonstrated tool use in a variety of contexts, including using a key to open a box (Lethmate, 1982), using stick tools made of bamboo or straw to extract raisins from a wooden box (O'Malley \& McGrew, 2000), and using wooden dowels to push or rake a food reward towards them in the trap tube task (Mulcahy \& Call, 2006). Orangutans are clearly capable of using different types of tools, and we wanted to investigate how they would progress towards the solution of the floating object task when it was possible for them to access a variety of materials to use as tools.

We hypothesized that both the orangutans would solve the task in the 'wet' condition. Because two Bornean orangutans in Hanus et al.'s (2011) study spat water into the tube in the dry tube condition (although they did not spit enough water in the tube to obtain the peanut), we thought it likely that at least 
one of our orangutans would also do so in the 'dry' condition. Finally, we hypothesized that both orangutans would make use of materials inside their enclosure as tools or use the stick tools we provided in the 'dry - stick tools' condition during at least one session, due to their previous experience with rigid tool use tasks.

\section{Method}

\section{Subjects}

Two orangutans (Pongo pygmaeus pygmaeus) residing at the Seneca Park Zoo in Rochester, NY were tested in this experiment. The female orangutan, Kumang, was 38-years-old (mother-reared to 18 months, then briefly hand-reared). The male orangutan, Denda, was 13-years-old (mother-reared). Denda and Kumang's female infant Bella (3-years-old) also lived in the enclosure with Kumang and Denda and was experimentally naïve. Bella was not tested in this experiment, although she was present during their test sessions (it was not permitted to separate Bella from Kumang, and it would have been difficult to test Bella without interference from Kumang). The adult orangutans were tested together (see procedure section). Kumang had extensive experience with problem-solving tasks involving stick tools. She had approximately 20 years of experience with an upright puzzle feeder that a zookeeper built for her (she had sporadic access to the puzzle feeder). She has also had experience with two very similar upright puzzle feeders in two recent experiments (Keller \& DeLong, 2016; O'Leary \& DeLong, 2016). Denda had previous experience with only Keller and DeLong's (2016) puzzle feeder. The zoo staff reported that Kumang and Denda had no previous experience with the floating object task or other tasks requiring the use of water as a tool, and they had never been trained to do any similar tasks.

Figure 1

Diagram Showing the Three Indoor and One Outdoor Orangutan Enclosures

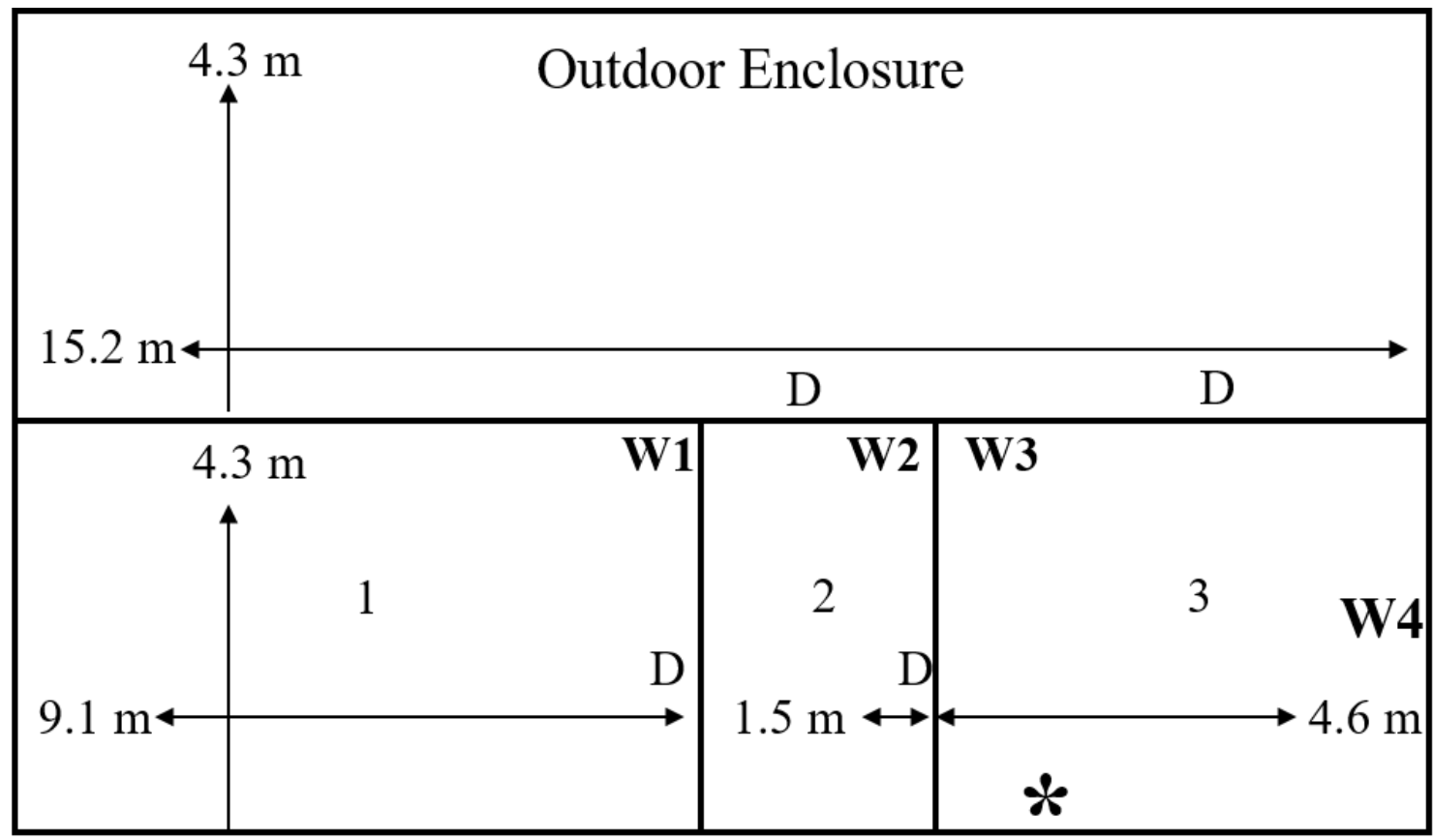

Note. The length and width of the enclosures are indicated. The apparatus was set up in the indoor enclosure 3 , with the position marked with a star (called 'experimental enclosure' in the text). Doors between enclosures are marked with a D. Water spigots $\mathrm{W} 1, \mathrm{~W} 2$, and $\mathrm{W} 3$ were $3.6 \mathrm{~m}$ above the floor, whereas $\mathrm{W} 4$ was $1.8 \mathrm{~m}$ above the floor. The subjects most often visited W3 and W4 during the sessions. Note that no new water spigots or dispensers were added for the purposes of the study. 
The orangutans were socially housed in an enclosure with three indoor rooms that were separated by doors as well as an outdoor area (Figure 1). Inside the indoor enclosures there were firehoses hanging from the ceilings, hammocks, and nets for them to climb on. The outdoor enclosure included a humanbuilt "termite mound" into which the animals could insert sticks to retrieve food items. Sometimes there was browse in the indoor and outdoor enclosures (e.g., hay) as well as various paper, plastic, cloth, and cardboard items. Every so often, other enrichment items were added to the enclosures (e.g., the animals were given sticks to obtain Jello from a dish affixed to the outside of the enclosure). Some enrichment devices utilized water (e.g., spraying hoses, water tubs, plastic pools). The orangutans' diet consisted of Mazuri primate biscuits, assorted fresh vegetables (approximately 500 calories), fresh fruit (approximately 100 calories), forage items (e.g., cereal or popcorn), unlimited greens (e.g., romaine lettuce, escarole) and unlimited browse (e.g., willow, maple, or mulberry).

All decisions regarding the animals' diet, management, and care were made by husbandry and veterinary personnel at the Seneca Park Zoo and were independent of their participation or accuracy in research sessions. The orangutans had access to peanuts only during the experimental sessions, but they were not food or water deprived during the course of the study. The experiments described here were approved by the Rochester Institute of Technology Institutional Animal Care and Use Committee (IACUC) and the Seneca Park Zoo Institutional Animal Care and Use Committee (IACUC) and comply with the current laws of the country (USA) in which they were performed.

\section{Materials}

A transparent vinyl tube $(23.6 \mathrm{~cm}$ in length, $4.7 \mathrm{~cm}$ diameter, $0.5 \mathrm{~cm}$ wall thickness) was used in this experiment, similar to the tube used in Mendes et al.'s (2007) study (see Figures 2 and 3). The bottom of the tube was closed, forming a water-tight container in which to place the peanut and water. The tube was stabilized with four wood blocks $(4.0 \mathrm{~cm}$ in width, $10.0 \mathrm{~cm}$ in length, $3.5 \mathrm{~cm}$ thick) and vertically attached to the outside of the enclosure using a U-bolt. Kumang broke the original apparatus during her second session. A new apparatus constructed in nearly the same way as the first one was used starting in the third session. The new apparatus was exactly the same as the first, except that the tube was attached to a sturdy polycarbonate plastic backing (38.1 cm in height, $24.4 \mathrm{~cm}$ in length, $1.0 \mathrm{~cm}$ wall thickness) and attached to the enclosure using two square U-bolts. The new backing prevented the orangutans from reaching the vinyl tube itself. The tools that were presented to the orangutans in the "dry-stick tools' condition were six wooden sticks derived from tree branches. Each tool was between 0.5 and $1 \mathrm{~cm}$ in diameter and $23.5 \mathrm{~cm}$ in length (see Figure 2). These tools were non-functional, in that the problem of obtaining the peanut could not be solved with the stick tools alone (water was required). The food reward placed in the tube apparatus in all sessions was a peanut inside its shell, which floated at the surface of the water.

The orangutans had continuous access to water through two water spigots in the experimental enclosure as well as two other spigots in indoor enclosures 1 and 2 (Figure 1). None were directly adjacent to the tube apparatus. Spigots W3 and W4 were nearest to the apparatus. Spigot W3 was $4.3 \mathrm{~m}$ behind the apparatus and $3.6 \mathrm{~m}$ above the ground, and spigot (W4) was $1.8 \mathrm{~m}$ above the ground and approximately $4 \mathrm{~m}$ to the right of the apparatus. The subjects most often used spigot W3 during the experimental sessions. All spigots were turned on with a button press (the button had to be held down to dispense water). All of these water spigots could be used by the orangutans to drink or obtain water, and none were novel or installed for the purpose of the experiment. The water spigots were installed prior to the arrival of both subjects to the zoo. No other water sources were available to solve the task during the experimental sessions. 


\section{Figure 2}

Tube Apparatus and Stick Tools
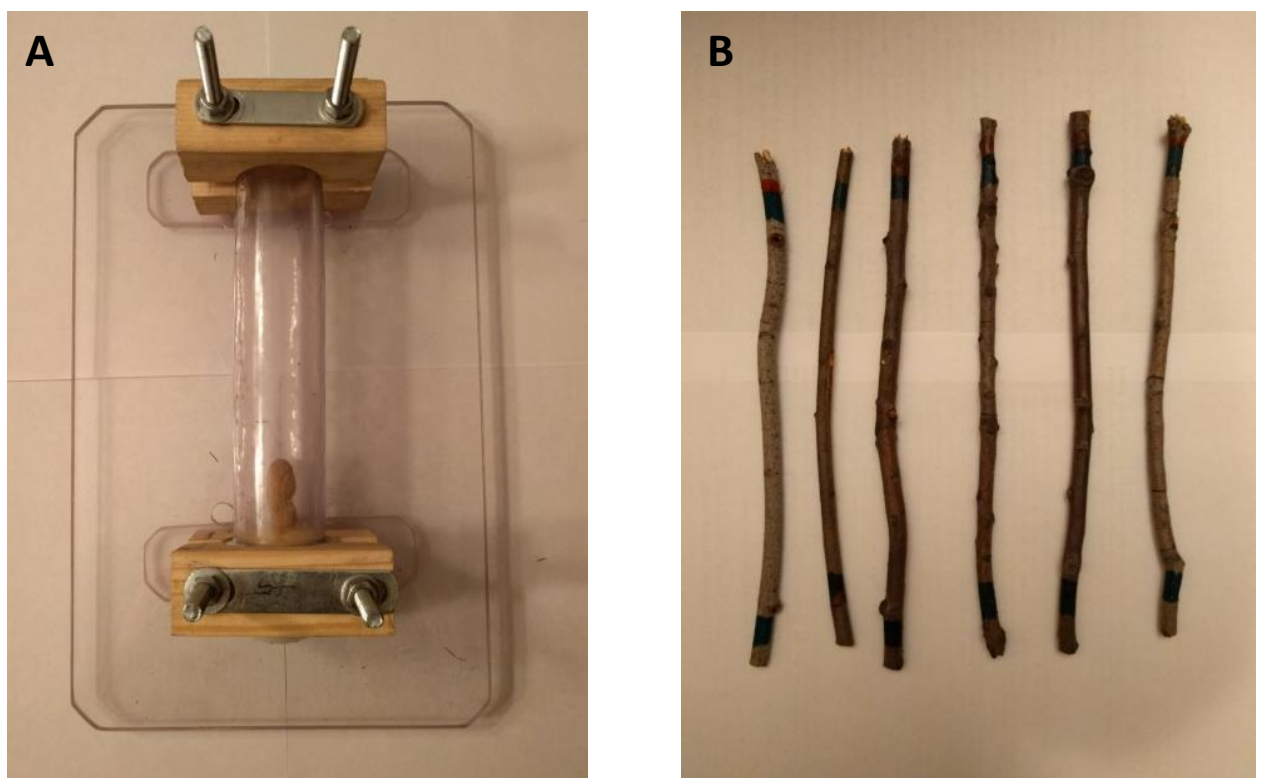

Note. A) The tube apparatus presented to the orangutans shown in the 'dry' condition with no water and a peanut in its shell on the bottom. In the 'wet' condition, the tube was one-quarter filled with water. The vinyl tube $23.6 \mathrm{~cm}$ in length, $4.7 \mathrm{~cm}$ diameter, $0.5 \mathrm{~cm}$ wall thickness) was attached to polycarbonate backing ( $38.1 \mathrm{~cm}$ in height, $24.4 \mathrm{~cm}$ in length, $1.0 \mathrm{~cm}$ wall thickness) to prevent the orangutans from breaking open the tube. B) Six stick tools $(23.5 \mathrm{~cm}$ in length, $0.5-1 \mathrm{~cm}$ diameter $)$ presented to the orangutans during the 'dry - stick tools' condition.

\section{Figure 3}

Both Orangutans Solving the Floating Object Task

A

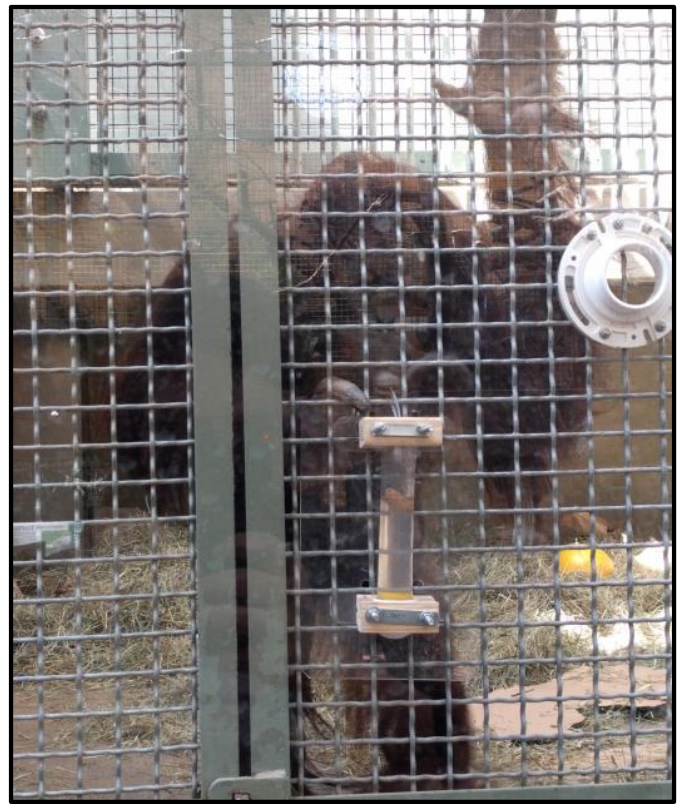

B

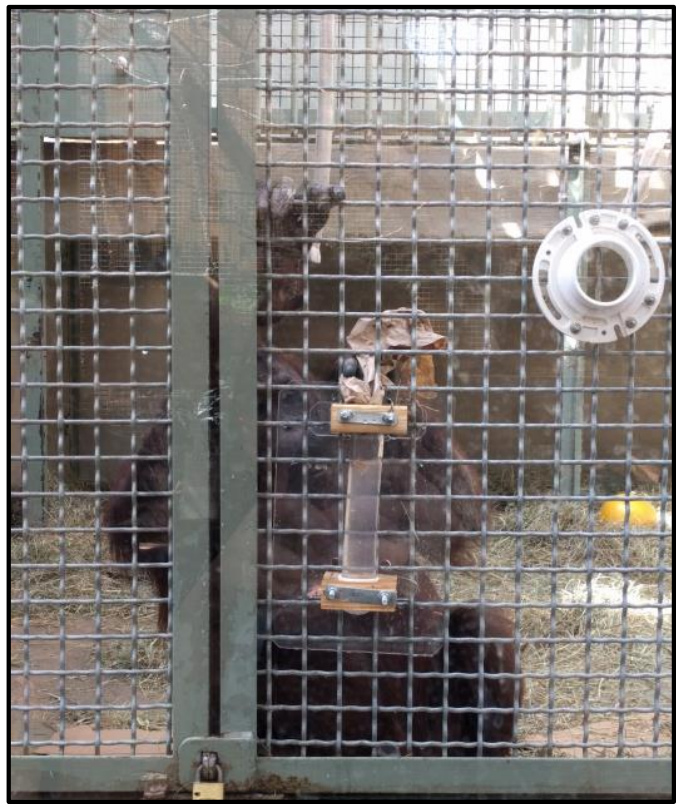

Note. A) Denda spitting water into the tube. B) Kumang using cardboard she made into a scoop to successfully pull the peanut out of the tube (after first spitting water into the tube). 


\section{Procedure}

The floating object task was presented in three conditions. In all conditions, the orangutans could not reach into the tube and pull out the peanut with their fingers in its initial position. In the 'wet' condition, the tube was one-quarter filled with water (to height of $5.9 \mathrm{~cm}$ in tube) while the peanut floated on top. In both dry conditions, the peanut rested on the bottom of the tube so that it was visible to the orangutans but no water was inside of the tube. In the 'dry' condition, no stick tools were provided. In the 'dry - stick tools' condition, six stick tools that were unnecessary for obtaining the reward were provided. These stick tools were very similar to those used by the orangutans in previous studies (Keller \& DeLong, 2016; O'Leary \& DeLong, 2016), as well as stick tools used by the orangutans during other enrichment activities. Each orangutan had six test sessions. Kumang was presented with the conditions in the following order: two sessions of the 'dry' condition, followed by two sessions of the 'dry - stick tools' condition, and ending with two sessions of the 'wet' condition. Denda's presentation order was slightly different due to an experimenter error and the task was presented as follows: one session of the 'dry' condition, one session of the 'dry - stick tools' condition session, the second session of the 'dry' condition, the second session of the 'dry - stick tools' condition, and finally the two sessions of the 'wet' condition.

Each orangutan completed only one session per day (dates are provided in Tables 1 and 2). All sessions began at 11 am though the day of the week varied (intervals between test sessions were determined by staff availability and a break for constructing a new apparatus when Kumang broke the first one). The orangutans had already been fed twice before 11 am (typically half their day's allotment of primate biscuits and some fruit and vegetables), but they had access to peanuts only during the test sessions. The zookeeper did not separate the three orangutans during the sessions (according to the directives of zoo personnel). Thus, all three animals could potentially reach the tube during the session for the target orangutan. However, in all sessions, the zookeeper attempted to keep the other adult orangutan occupied with food and other enrichment activities (e.g., teeth brushing) while the target orangutan was attempting the task. Both orangutans responded to these distraction activities at the beginning of each session. However, Denda entered the experimental enclosure at some point in all of Kumang's sessions and Kumang entered the experimental enclosure during one of Denda's sessions (see Tables 1 and 2). No attempt was made to engage Kumang's daughter, Bella, away from the task and she often closely observed each of her parents attempting to solve the task and occasionally interacted with the apparatus (she was present during all of Kumang's sessions and all but one of Denda's sessions, see Tables 1 and 2). The orangutan that was the first to enter the experimental enclosure was tested first (in the five sessions where both orangutans were tested, Denda was tested first three times and Kumang was tested first two times; see Tables 1 and 2).

In the beginning of the session, the keeper set up the task by attaching the apparatus to the outside of the enclosure using square U-bolts, in the same location for all sessions. During only the "dry - stick tools' condition sessions, the keeper placed the stick tools on the ground to the right of the tube apparatus. The session began once the orangutan entered the enclosure with the tube apparatus. As soon as the door to the experimental enclosure was opened for the orangutans to come through, the zookeeper would begin to attempt to distract the other adult orangutan who had not entered the enclosure (with food or other enrichment activities). Each session ended as soon as the individual peanut was extracted, $30 \mathrm{~min}$ had elapsed, or something else occurred requiring the end of the session (e.g., the apparatus breaking, the other orangutan solved the task). The orangutan's standard water spigots (mentioned above) were available to them during all conditions. When one orangutan's session was complete, the zookeeper would coax all the orangutans out of the experimental enclosure with a food reward (e.g., lettuce, fruit). This method was always successful. The zookeeper would then close the door to the experimental enclosure and set up the apparatus for the session with the other orangutan. 
Table 1

Denda's Test Sessions

\begin{tabular}{|c|c|c|c|c|c|c|c|c|c|}
\hline Session & Date & Condition $^{\mathrm{a}}$ & Out $^{b}$ & Used Tool $^{\mathrm{c}}$ & $\begin{array}{c}\text { Made }^{\mathrm{d}} \\
\text { Tool }\end{array}$ & $\begin{array}{c}\text { Spit }^{\mathrm{e}} \\
\text { Water }\end{array}$ & Interact $^{\mathrm{f}}$ & $\begin{array}{l}\text { Time }^{\mathrm{g}} \\
(\mathrm{min})\end{array}$ & Success ${ }^{\mathrm{h}}$ \\
\hline 1 & Mar 8* & Dry & Yes & Stick & Stick & $\operatorname{Yes}(2)$ & Bella & 13 & Yes \\
\hline 2 & $\operatorname{Mar} 29 *$ & Dry-stick tools & No & $\begin{array}{c}\text { Stick, } \\
\text { Plastic Bag }\end{array}$ & $\begin{array}{c}\text { Paper } \\
\text { Tube }\end{array}$ & $\operatorname{Yes}(2)$ & $\begin{array}{c}\text { Bella, } \\
\text { Kumang }\end{array}$ & 12 & Yes \\
\hline 3 & Apr $3^{\#}$ & Dry & No & Stick, Hay & No & $\operatorname{Yes}(2)$ & Bella & 5 & Yes \\
\hline 4 & Apr 12 & Dry-stick tools & No & Stick & No & Yes(3) & Bella & 4 & Yes \\
\hline 5 & Apr 17 & Wet & Yes & Stool & No & Yes(2) & Bella & $<1$ & Yes \\
\hline 6 & Apr 19* & Wet & Yes & No & No & $\operatorname{Yes}(3)$ & No & 2 & Yes \\
\hline
\end{tabular}

Note. New tube apparatus in session 2 because Kumang broke the first apparatus on March 15 before Denda was tested. *Denda was tested before Kumang these dates. "Denda was the only subject tested on this date.

a In the 'wet' condition, the tube was quarter-filled with water; in the 'dry - stick tools' condition, the tube had no water and six stick tools that were unnecessary for obtaining the reward were provided; and in the and 'dry' condition the tube had no water and no stick tools were provided. ${ }^{\mathrm{b}}$ indicates whether the orangutan had access to their outside enclosure, which had additional enrichment items that could be used as tools. Access was determined by the zookeeper, who closed the outside door when the temperature was below $45^{\circ}$.

${ }^{c}$ indicates whether the orangutan used any tool during their session (one provided by us or one of their own)

${ }^{d}$ indicates whether the orangutan made a tool during their session.

${ }^{\mathrm{e}}$ indicates whether the orangutan spat water into the tube during the session. The number of times the orangutan spat water into the tube is in parentheses.

${ }^{\mathrm{f}}$ indicates which other orangutans interacted with the target subject or the apparatus during the session.

$\mathrm{g}$ indicates total session time (session ends after peanut is retrieved)

${ }^{\mathrm{h}}$ success is defined as extracting the peanut by spitting water into the tube or spitting water into the tube and using an additional tool

Table 2

Kumang's Test Sessions

\begin{tabular}{|c|c|c|c|c|c|c|c|c|c|}
\hline Session & Date & Condition $^{\mathrm{a}}$ & Out $^{\mathrm{b}}$ & Used Tool $^{\mathrm{c}}$ & Made Tool ${ }^{\mathrm{d}}$ & $\begin{array}{c}\text { Spit }^{\mathrm{e}} \\
\text { Water }\end{array}$ & Interact $^{\mathrm{f}}$ & $\begin{array}{l}\text { Time }^{g} \\
(\mathrm{~min})\end{array}$ & Success $^{\mathrm{h}}$ \\
\hline 1 & Mar 8 & Dry & Yes & No & No & No & $\begin{array}{l}\text { Denda, } \\
\text { Bella }\end{array}$ & 11 & No \\
\hline 2 & Mar $15^{\#}$ & Dry & Yes & Cloth, Hay & No & No & $\begin{array}{l}\text { Denda, } \\
\text { Bella }\end{array}$ & 19 & No \\
\hline 3 & Mar 29 & Dry-stick tools & No & $\begin{array}{l}\text { Stick, Ball, } \\
\text { Plastic bag }\end{array}$ & Paper Tube & No & $\begin{array}{l}\text { Denda, } \\
\text { Bella }\end{array}$ & 23 & No \\
\hline 4 & Apr $12 *$ & Dry-stick tools & No & Stick, Hay & No & $\operatorname{Yes}(2)$ & $\begin{array}{l}\text { Denda, } \\
\text { Bella }\end{array}$ & 29 & Yes \\
\hline 5 & Apr 17* & Wet & Yes & Stool, Hay & No & Yes(1) & $\begin{array}{l}\text { Denda, } \\
\text { Bella }\end{array}$ & 7 & Yes \\
\hline 6 & Apr 19 & Wet & Yes & Paper, Hay & $\begin{array}{l}\text { Cardboard } \\
\text { Tube/Scoop }\end{array}$ & Yes(1) & $\begin{array}{l}\text { Denda, } \\
\text { Bella }\end{array}$ & 13 & Yes \\
\hline
\end{tabular}

Note. New tube apparatus in session 3 because Kumang broke the first apparatus during session 2 on March 15 . Kumang was tested before Denda these dates. "Kumang was the only subject tested on this date.

an the 'wet' condition, the tube was quarter-filled with water; in the 'dry- stick tools' condition, the tube had no water and six stick tools that were unnecessary for obtaining the reward were provided; and in the and 'dry' condition the tube had no water and no stick tools were provided.

${ }^{\mathrm{b}}$ indicates whether the orangutan had access to their outside enclosure, which had additional enrichment items that could be used as tools. Access was determined by the zookeeper, who closed the outside door when the temperature was below $45^{\circ}$.

${ }^{\mathrm{c}}$ indicates whether the orangutan used any tool during their session (one provided by us or one of their own)

$\mathrm{d}$ indicates whether the orangutan made a tool during their session.

${ }^{\mathrm{e}}$ indicates whether the orangutan spat water into the tube during the session. The number of times the orangutan spat water into the tube is in parentheses.

${ }^{\mathrm{f}}$ indicates which other orangutans interacted with the target subject or the apparatus during the session.

${ }^{\mathrm{g}}$ indicates total session time (session ends after peanut is retrieved, the apparatus broke, another animal spit water in the tube, or subject abandons apparatus without returning before 30 minutes elapsed)

${ }^{\mathrm{h}}$ success is defined as extracting the peanut by spitting water into the tube or spitting water into the tube and using an additional tool 


\section{Video Recording and Coding}

A Nikon D3100 camera was used to videotape all sessions. The camera sat on a Manfrotto tripod outside of the experimental enclosure (see Figure 1) in the visitor viewing area. The camera was kept on the tripod, except when the orangutan left the experimental enclosure in which case the camera was taken off the tripod and handheld while the orangutan was in another inside enclosure. If the target orangutan went to the outside enclosure, the camera was set back on the tripod until the orangutan returned. Two individuals viewed and coded the videos, the experimenter and an individual who was not present during the sessions (the second coder). We coded success, latency to success/end of session, latency to first spit, latency to subsequent spits, and number of spits. A successful session was defined as the orangutan obtaining the peanut by either spitting water in the tube to completely fill it, or spitting water into the tube (so that the tube was about $90 \%$ filled with water) and then using a finger or an additional tool to retrieve the peanut (see Figure 3B). The second coder coded all these measures in $100 \%$ of the sessions for both orangutans. Reliability was excellent (Pearson's correlation coefficient: success, $r=1.000$; latency to success/end, $r=.995$; latency to first spit, $r=.993$; latency to subsequent spits, $r=.998$; number of spits, $r=1.000)$.

We also coded the total length of time the orangutans were engaged in specific behaviors during a session. These behaviors included hand/feet contact with the apparatus (e.g., pulling or hitting the apparatus, inserting a finger into the tube), mouth contact with the apparatus (e.g., biting or chewing the apparatus), contact between our provided stick tools (in the 'dry - stick tools' condition) and the apparatus (e.g., inserting the stick in the tube or poking the apparatus with the stick), contact between the tools used by the orangutans (which were not our stick tools) and the apparatus (e.g., throwing a ball at the apparatus, inserting pieces of straw into it), and time spent making tools (e.g., crafting a cardboard tube into a scoop to extract the peanut). The second coder coded all these measures in $33 \%$ of the sessions for both orangutans. Reliability was excellent (Pearson's correlation coefficient: hand/feet contact with the apparatus, $r=.994$; mouth contact with the apparatus, $r=.999$; contact between our provided stick tools and the apparatus, $r=.999$; contact between the tools used by the orangutans and the apparatus (not our stick tools), $r=.998$; and time spent making tools, $r=.999$ ).

\section{Results}

Denda was successful in all six sessions across all three conditions (Table 1). Kumang was successful in three of six sessions in two conditions; one 'dry - stick tools' session and both 'wet' sessions (Table 2). Only Denda succeeded in the 'dry' condition, and he obtained the peanut in his first session. Both orangutans succeeded in both sessions of the 'wet' condition. Denda always obtained the peanut by spitting water into the tube two or three times, whereas Kumang obtained the peanut by spitting water into the tube twice in her first successful session (Session 4) then subsequently used one mouthful of water plus her finger or an additional tool she made (cardboard scoop) to extract the peanut in her final two sessions (see Figure 3B).

Denda successfully obtained the peanut faster than Kumang. His average solution time across six sessions was $6.1 \mathrm{~min}$, and Kumang's average solution time across three sessions was 16.3 min (see Tables 1 and 2). Both Denda and Kumang's latency to spit water into the tube decreased exponentially across sessions (Figure 4). Denda's latency to first spit sharply decreased from Session 1 to Session 2 (750 s to $191 \mathrm{~s})$, gradually decreased between Sessions 2 and 4, then was less than $30 \mathrm{~s}$ for his final three sessions (exponential decrease in latency to first spit; $y=1065.5 \mathrm{e}^{-0.791 x}, R^{2}=0.94$ ). Denda's latency to second spit decreased in the same exponential pattern as his latency to first spit, with the second spit happening in under one minute in the final three sessions $\left(\mathrm{y}=1816.4 \mathrm{e}^{-0.733 \mathrm{x}}, R^{2}=0.94\right)$. Kumang's latency to first spit also decreased exponentially from her first to her third successful session ( $465 \mathrm{~s}$ to $123 \mathrm{~s} ; \mathrm{y}=6166 \mathrm{e}^{-0.665 \mathrm{x}}$, $\left.R^{2}=0.96\right)$. Kumang's shortest latency (123 s in Session 6) was longer than Denda's latency to first spit in his final four sessions $(M=35.8 \mathrm{~s})$. 
Figure 4

Spitting Behavior
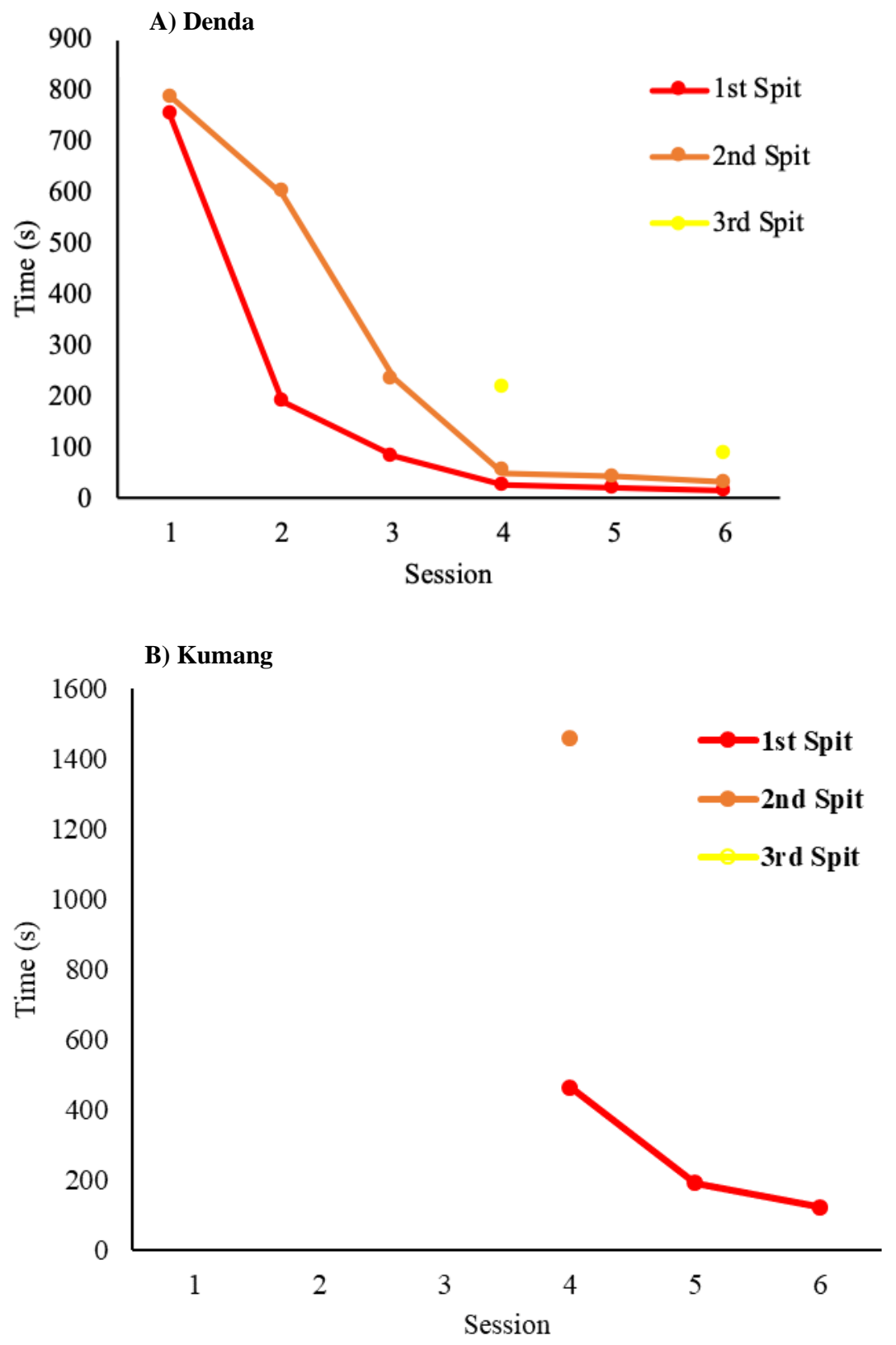

Note. The first spit latency is defined as the amount of time between when the session starts and when the orangutan begins to spit water into the tube for the first time. The second spit latency is defined as the amount of time between when the session starts and when the orangutan begins to spit water into the tube for the second time. The third spit latency is defined as the amount of time between when the session starts and when the orangutan begins to spit water into the tube for the third time. Kumang's first successful spit of water into the tube did not occur until Session 4. In Sessions 5 and 6, Kumang spat into the tube only once and used an additional tool to retrieve the peanut.

Both orangutans used the stick tools we provided in the 'dry - stick tools' condition during both sessions to try to obtain the peanut (Figure 5). Denda used our stick tools in his first 'dry - stick tools' session for $66 \mathrm{~s}$, and again in his second 'dry - stick tools' session for $41 \mathrm{~s}$ (total of $1.8 \mathrm{~min}$ ). Kumang used our stick tools in her first 'dry - stick tools' session for $79 \mathrm{~s}$, and again in her second 'dry - stick tools' session for $980 \mathrm{~s}$ (total of $17.7 \mathrm{~min}$ ). Kumang handled these stick tools for much longer than 
Denda. She persisted with using our stick tools, pieces of hay (like chopsticks), a cardboard scoop, and her fingers to remove the peanut after she spat water into the tube.

\section{Figure 5}

Time Spent Engaged in Different Behaviors in the Test Sessions
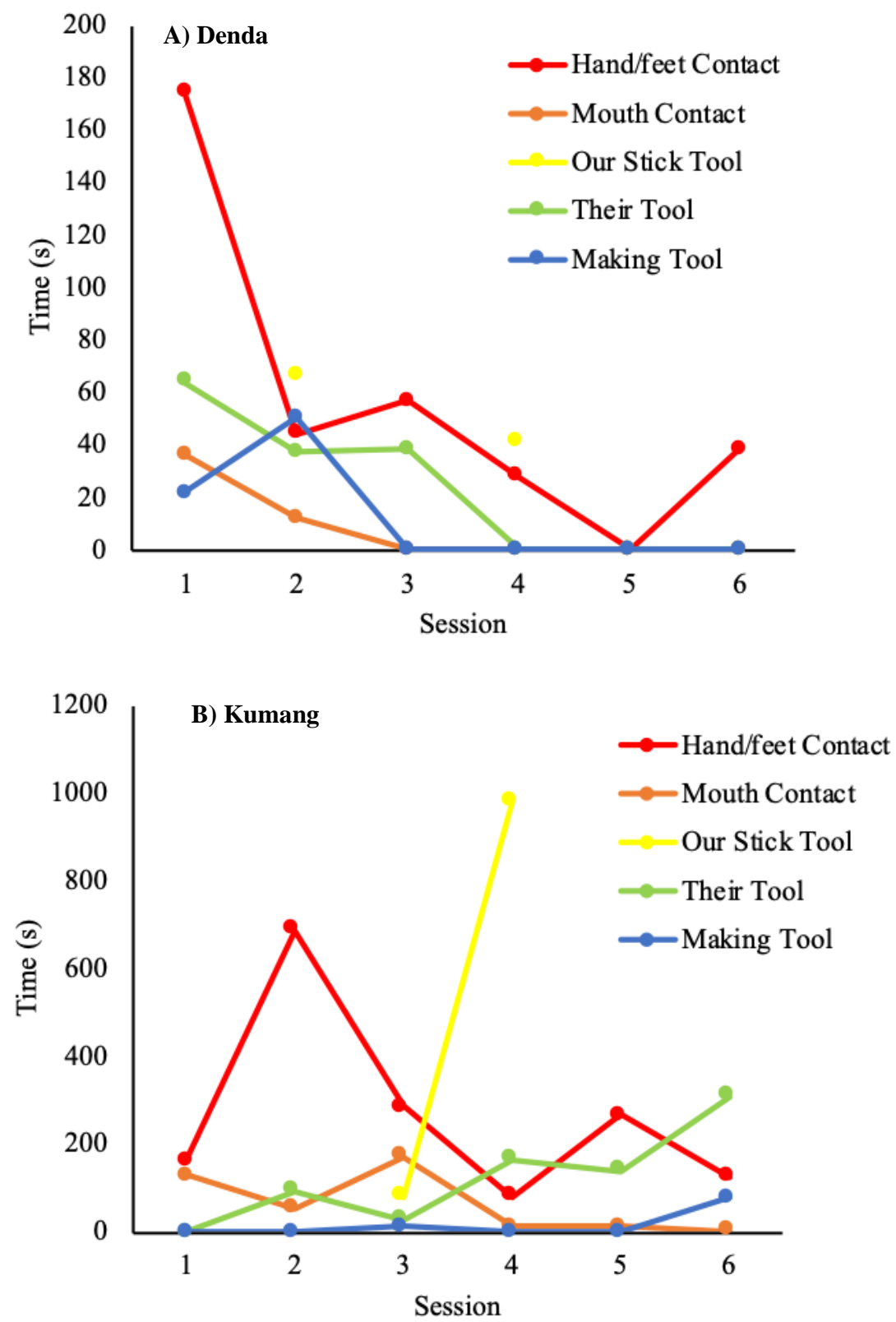

Note. 'Hand/feet contact' refers to the time the orangutan's hands or feet were touching the apparatus. 'Mouth contact' refers to the time the orangutan's mouth was touching the apparatus. 'Our stick tool' refers to the time the stick tools we provided came in contact with the apparatus during the 'dry - stick tools' condition. 'Their tool' refers to the time another item from the enclosure the orangutan was used as a tool to retrieve the peanut. 'Making tool' refers to the time the orangutan was engaged in manufacturing a tool using their hands, feet, or mouth out of paper, hay, sticks, or cardboard provided in their enclosure by the zoo staff.

Both orangutans also used materials that they found in their enclosure as tools (e.g., sticks, plastic bag, hay, cloth, ball, paper) to attempt to retrieve the peanut (these tools were different than the stick tools 
we provided them). Denda used a tool (e.g., hay, stick, paper tube) in five of his six sessions, ignoring these tools only in Session 6 (see Table 1 and Figure 5). Kumang also used a tool in five of her six sessions, forgoing tool use only in Session 1 where she tried to bite through the tube (see Table 2 and Figure 5). Interestingly, both orangutans also manufactured tools (e.g., rolling a paper tube, breaking/modifying a stick). Denda did this in two of his six sessions and did not engage in tool manufacture after Session 2 (Table 1). Kumang also made tools in two sessions; Sessions 3 and 6 (Table 2).

Because we could not separate the orangutans during testing, they could interact with each other and the apparatus during test sessions of the target orangutan (see Tables 1 and 2). Denda entered the experimental enclosure during all of Kumang's test sessions. When Denda was present in Kumang's first three sessions, he spat water into the tube once in each of her first and second sessions (not enough to obtain the peanut) and twice in her third session (Kumang obtained and ate the peanut in her third session after Denda's second spit). Denda was present in the room but did not interact with the apparatus in Kumang's fourth and fifth sessions and only briefly interacted with it in her sixth session (without spitting any water in it). When Kumang was present in Denda's second session, she pulled on the tube for about $30 \mathrm{~s}$ but did not spit water into it (she did not enter the experimental enclosure for any of his other sessions).

\section{Discussion}

Both Bornean orangutans successfully solved the floating object task. However, the male Denda solved the task in the first session ('dry' condition) and across all conditions whereas the female Kumang solved the task in only her final three sessions. These results represent the first evidence that Bornean orangutans ( $P$. pygmaeus) can spontaneously solve the floating object task. None of the 10 Bornean orangutans in Hanus et al.'s (2011) study solved the task, although one male and one female spat into the tube without reaching the peanut. In addition, this is also the first report of an orangutan solving the floating object task in the 'dry' condition first (without the cue of water present in the tube), which is a more cognitively demanding task. Sumatran orangutans (P. abelii) in Mendes et al.'s (2007) study successfully solved the floating object task but were presented first with the condition in which the tube was one-quarter filled with water. Four of the five orangutans from Mendes et al.'s (2007) study solved the floating object task again nine years later in a re-test (Ebel et al., 2019). Taken together with previous research, the results of the current study suggest that both Bornean and Sumatran orangutans are capable of using water to solve the floating object task (Ebel et al., 2019; Mendes et al., 2007). It remains to be seen whether this ability is limited to a small proportion of individuals in a population.

There were differences in performance between the Bornean orangutans in the current study and the apes tested in previous studies using the floating object task. One must keep in mind when comparing studies that there were important methodological differences between studies that undoubtedly influenced the results (e.g., we did not separate the subjects during testing, the presence of other tools in our enclosure). All five Sumatran orangutans in Mendes et al.'s (2007) study achieved success in the first session and consistently used the same solution in all subsequent sessions. After the first session, the subjects had very little hand or mouth contact with the tube apparatus. In the present study, Denda also succeeded in the first session and all remaining sessions, but he continued to use a variety of approaches (using other tools like sticks and hay, pulling or chewing the apparatus) in the first three sessions. Denda took longer to achieve success in the first session (786 s) than the orangutans in Mendes et al.'s (2007) study, who required $540 \mathrm{~s}$ on average to solve the task in the first session. This difference in time may be due to Denda being presented with the 'dry' condition in the first session as opposed to the Sumatran orangutans solving the task first in the 'wet' condition (the 'dry' condition is more challenging). However, the time required to solve the problem decreased exponentially across sessions for both Denda and Mendes et al.'s (2007) subjects. Kumang's behavior was quite different from the orangutans in Mendes et al.'s (2007) study, as she failed to solve the task by pulling on it and biting it in the first three sessions, and also continued to make use of other tools in the enclosure to obtain the peanut even after she 
successfully spat water into the tube in her fourth session. In addition, the orangutans in the current study needed only one to three spits of water, whereas the Sumatran orangutans in Mendes et al.'s (2007) study used three to five spits, and the chimpanzees in Hanus et al.'s (2011) and Ebel et al.'s (2019) studies appeared to use an average of approximately 3.5 to 7 spits to solve the task. It is possible that fewer spits could make the task easier, as less persistence is required and visual feedback is stronger if the peanut is closer to the top after the first spit.

The presence of other potential tools (in addition to water) in the orangutans' enclosures during the experimental sessions was one difference between the current study and other studies utilizing the floating object task (Ebel et al., 2019; Hanus et al., 2011; Mendes et al., 2007; Tennie et al., 2010). Because orangutans can use many types of tools, as well as make tools (e.g., Galdikas, 1982; Mulcahy \& Call, 2006; O’Malley \& McGrew, 2000; Seed \& Byrne, 2010; van Schaik et al., 1996; van Schaik \& Knott, 2001), providing an environment with many objects that could be used as tools increased the ecological validity of the experiment (making it more similar to their natural habitat). In addition, since water was not the only tool available to the animals, it made it more difficult for them to zero in on the correct solution of using water as a tool (a stronger test of the use of water as a tool). In fact, both Denda and Kumang made and used other tools throughout the test sessions, even after they correctly solved the task using water (e.g., sticks, hay, paper, cardboard). Possibly, they did not realize that water was the most effective tool to use (at least some water was necessary to solve the task, although Kumang did obtain the peanut using a combination of water and her finger or another tool in her final two sessions), or they just perseverated on other tools that were more familiar to them.

Our subjects had many years of experience using stick tools, particularly Kumang. With that in mind, in the 'dry - stick tools' condition, we provided stick tools very similar to those that had been useful to our subjects in a prior task in which they had to push peanuts through an upright maze (Keller \& DeLong, 2016; O'Leary \& DeLong, 2016). Kumang may have been more likely to use our provided stick tools compared to Denda given that she participated in both prior studies (he did only one), and she had over twenty years of experience with the same types of upright mazes built by her keepers for enrichment. In addition, Kumang used stick tools consistently and well in these prior upright maze tasks as opposed to Denda, who often preferred to use his fingers to extract the peanuts instead of the stick tool in Keller and DeLong's (2016) study. Both orangutans attempted to use our stick tools to obtain the peanut in the tube (unsuccessfully), but Kumang handled our stick tools much longer than Denda (especially in the fourth session). Denda actually used a stick he found in his enclosure (not provided by us) in two additional sessions, which may indicate that he thought all sticks (not just our familiar stick tools) were worthy potential tools. Because there were only two subjects in this study, it is not possible to determine whether their handling of the stick tools was due to their prior experience with stick tools, personal preference to use stick tools, or some other factor.

Denda solved the task in his first session. Whether Denda's performance is a result of insightful problem solving or some other process is open to interpretation. Kohler (1925) coined the term 'insight' to explain a way in which animals can solve problems. In Kohler's (1925) classic study, chimpanzees stacked boxes on top of each other to reach a banana hanging from the ceiling. Kohler (1925) describes how the chimpanzee Sultan first tried to jump up and retrieve the reward, and when that failed he "suddenly stood still in front of the box, seized it, ...began to climb upon it... and springing upwards with all his force, tore down the banana" (p. 40). Shettleworth (2012) defined insightful behavior as "sudden success after an impasse, that is, after a period of unrelated successful behavior as distinct from approximation through trial and error" (p. 224). To show insightful behavior, the task is novel, there is no training provided, and no opportunity for social learning. After a period of ineffective strategies, it appears as though the individual suddenly acquires the correct solution (the "aha" moment described by humans; Bowden et al., 2005).

Denda did not have training in any task that would require water as a tool (that we know of), he had never experienced the floating object task prior to the current study, and he was the first subject we tested (before Kumang's first session, and she did not enter the experimental enclosure during his session). In his first session, he pulled on the apparatus and bit it, then inserted a stick tool (he stripped the 
stick to make it thinner after trying it once to see if it would work better), then obtained two mouthfuls of water to solve the task. Prior to his first mouthful of water, he did not appear to approach any water spigots. According to the zookeeper, prior to the study, Denda would sometimes fill his mouth with water from a water spigot and drench Kumang from overhead to induce a play session (he would occasionally do this to an unfamiliar human as well but Kumang was not known to do this). Thus, Denda did have experience spitting on live individuals, but he was not known to spit water into containers. Once acquired, he successfully applied this spitting behavior to all his test sessions. Denda solved the task faster across the six sessions, but he solved the task immediately (i.e., in two minutes or less) only in his final two sessions. That he did not solve the task immediately in all sessions following his first one could argue against describing his behavior as insightful. An alternative view of Denda's behavior is that he had solved some similar problem with water in his past (unknown to us) and simply remembered that behavior, or did not know the water would raise the peanut in the tube and spat into it in frustration (then, seeing the result, got a second mouthful of water). We cannot determine the mechanism responsible for Denda's success. Mendes et al. (2007) attributed the success of five female Sumatran orangutans on the floating object task to be the result of insightful problem solving. Mendes et al. (2007) suggested that one way to elucidate whether the apes were actually using insightful problem solving is to test a group of subjects with an opaque tube that prevents them from seeing the results of their actions (this would help differentiate between the possibility that they came up with a fully-formed solution prior to the first spit and the possibility that the sight of water in the tube prompted further spitting). Ebel et al. (2019) showed that none of 24 sanctuary-living chimpanzees deprived of visual feedback (an opaque tube) in baseline sessions solved the floating object task, which may argue against the insightful solution interpretation of the results in the current and prior studies.

It is unclear how Kumang solved the task in her fourth session. It is a limitation of our study that we were unable to separate the subjects for testing, so we could not differentiate between individual and social learning in this setting. In addition, our experimental design was not set up to allow for the possibility of rigorously assessing social learning [in contrast to Tennie et al.'s (2010) study]. Social learning can be defined as "learning that is influenced by observation of, or interaction with, another animal (typically a conspecific) or its products" (Heyes, 1994, p. 207). There are many different social learning processes, including imitation, emulation, observational conditioning, and stimulus and local enhancement (Whiten et al., 2004). It is difficult to know whether Kumang solved the task because she spontaneously came up with the solution on her own, her attention was drawn to the water spigot because she saw Denda there (enhancement), she was emulating the end-state of the task (having observed the peanut floating in the water in the tube after Denda spat water into the tube), she was imitating his spitting action, or some other process.

Caution must be used when interpreting the results from the current study because there were only two orangutan subjects ( $P$. pygmaeus). Other studies using the floating object task with five orangutans (P. abelii; Mendes et al., 2007 and Ebel et al., 2019), five gorillas (G. gorilla; Hanus et al., 2011), and seven brown capuchin monkeys (C. apella; Renner et al., 2017) also had a relatively low number of subjects. However, some studies drawing from multiple populations including sanctuaries and primate research centers were able to utilize a larger sample size. Hanus et al. (2011) tested 10 orangutans ( $P$. pygmaeus) and 25 chimpanzees ( $P$. troglodytes). Ebel et al. (2019) tested 24 chimpanzees $(P$. troglodytes) in Experiment 1 and 18 chimpanzees in Experiment 2. Tennie et al. (2010) tested 32 chimpanzees (P. troglodytes). We tested all the orangutans (except the three-year-old) that were housed at the Seneca Park Zoo, which included one adult female and one adult male. A single subject is all that is needed to show that Bornean orangutans are capable of solving the floating object task, which our study has done. Future studies should replicate this task with a larger sample size of female and male Bornean orangutans of different ages and different levels of experience with various tools. It would be interesting to investigate if other orangutans with exposure to enrichment objects and experience using other rigid tools such as sticks, keys, or rakes in problem solving tasks perseverate on those types of rigid tools when presented with the floating object task. 
In conclusion, we have shown that two Bornean orangutans ( $P$. pygmaeus) spontaneously solved the floating object task, but the mechanism underlying their success remains unclear. This work is in agreement with Mendes et al.'s (2007) study showing that five Sumatran orangutans (P. abelii) could solve the same difficult task that typically has a low success rate in nonhuman primates. The present study is consistent with other research demonstrating orangutans' use of tools (e.g., Lethmate, 1982; Mulcahy \& Call, 2006; O'Malley \& McGrew, 2000). Orangutans, like archerfish or stingrays, can use water as a tool (Kuba et al., 2010; Schuster et al., 2004). More studies are needed to investigate whether other nonhuman animals can use water as a tool.

\section{Acknowledgments}

We are grateful to the Seneca Park Zoo (Rochester, NY) for allowing us to work with their orangutans. We especially thank zoologist Brian Sheets for his assistance with the experimental sessions, diagram of the enclosure, and comments on the manuscript. We appreciate the logistical support provided by David Hamilton and John Adamski at the Seneca Park Zoo. In addition, we thank Peter Burnett and Tony Weiler for helping to construct the apparatus used in this experiment. This project was approved by the both the RIT and the Seneca Park Zoo Institutional Animal Care and Use Committees.

\section{References}

Alcock, J. (1972). The evolution of the use of tools by feeding animals. Evolution, $26,464 \mathrm{e} 473$. https://doi.org/10.1111/j.1558-5646.1972.tb01950.x

Beck, B. B. (1980). Animal tool behavior: The use and manufacture of tools. Garland STPM Press.

Bird, C. D., \& Emery, N. J. (2009). Rooks use stones to raise the water level to reach a floating worm. Current Biology, 19(16), 1410-1414. https://doi.org/10.1016/j.cub.2009.07.033

Bowden, E., Beeman, M., Fleck, J., \& Kounios, J. (2005). New approaches to demystifying insight. Trends in Cognitive Sciences, 9, 322-328. https://doi.org/10.1016/j.tics.2005.05.012

Bshary, R., Wickler, W., \& Fricke, H. (2002). Fish cognition: A primate's eye view. Animal Cognition, 5, 1-13. https://doi.org/10.1007/s10071-001-0116-5

Cheke, L. G., Bird, C. D., \& Clayton, N. S. (2011). Tool-use and instrumental learning in the Eurasian jay (Garrulus glandarius). Animal Cognition, 14, 441-455. https://doi.org/10.1007/s10071-011-0379-4

Cheke, L. G., Loissel, E., \& Clayton, N. S. (2012). How do children solve Aesop's fable? PLoS One, 7, e40574. https://doi.org/10.1371/journal.pone.004050574

Ebel, S. J., Schmelz, M., Herrmann, E., \& Call, J. (2019). Innovative problem solving in great apes: The role of visual feedback in the floating peanut task. Animal Cognition, 22, 791-805. https://doi.org/10.1007/s1007019-01275-0

Galdikas, B. M. F. (1982). Orangutan tool-use at Tanjung Puting Reserve, Central Indonesian Borneo (Kalimantan Tengah). Journal of Human Evolution 11(1), 19-24. https://doi.org/10.1016/S0047-2484(82)80028-6

Gormley, R. (2015). Problem solving and tool use in three species of otter [Unpublished master's thesis]. The University of Tennessee at Chattanooga.

Hanus, D., Mendes, N., Tennie, C., \& Call, J. (2011). Comparing the performance of apes (Gorilla gorilla, Pan troglodytes, Pongo pygmaeus) and human children (Homo sapiens) in the floating peanut task. PLoS One, 6, e19555. https://doi.org/10.1371/journal.pone.0019555

Heyes, C. M. (1994). Social learning in animals: Categories and mechanisms. Biological Reviews, 69, $207-231$. https://doi.org/10.1111/j.1469-185X.1994.tb01506.x

Jelbert, S. A., Taylor, A. H., Cheke, L. G., Clayton, N. S., \& Gray, R. D. (2014). Using the Aesop's fable paradigm to investigate causal understanding of water displacement by New Caledonian crows. PLoS One, 9, e92895. https://doi.org/10.1371/journal.pone.0092895

Jelbert, S. A., Taylor, A. H., \& Gray, R. D. (2015). Investigating animal cognition with the Aesop's fable paradigm: Current understanding and future directions. Communicative and Integrative Biology, 8, e1035846. https://doi.org/10.1080/19420889.2015.1035846

Keller, A. M., \& DeLong, C. M. (2016). Orangutans (Pongo pygmaeus pygmaeus) and children (Homo sapiens) use stick tools in a puzzle box task involving semantic prospection. International Journal of Comparative Psychology, 29, 1-25. Retrieved from: http://escholarship.org/uc/item/4b5481gp 
Kohler, W. (1925). The mentality of apes. Harcourt, Brace, and World.

Kuba, M., Byrne, R., \& Burghardt, G. (2010). A new method for studying problem solving and tool use in stingrays (Potamotrygon castexi). Animal Cognition, 13, 507-513. https://doi.org/10.1007/s10071-009-0301-5

Lethmate, J. (1982). Tool-using skills of orangutans. Journal of Human Evolution, 11, 49-64. https://doi.org/10.1016/S0047-2484(82)80031-6

Logan, C. J. (2016). Behavioral flexibility and problem solving in an invasive bird. PeerJ, 4, e1975. https://doi.org/10.7717/peerj.1975

Logan, C. J., Harvey, B. D., Schlinger, B. A., \& Rensel, M. (2016). Western scrub-jays do not appear to attend to functionality in Aesop's fable experiments. PeerJ, 4, e1707. https://doi.org/10.7717/peerj.1707

Mendes, N., Hanus, D., \& Call, J. (2007). Raising the level: Orangutans use water as a tool. Biology Letters, 3, 453455. https://doi.org/10.1098/rsbl.2007.0198

Miller, R., Jelbert, S. A., Loissel, E., Taylor, A. H., \& Clayton, N. (2017). Young children do not require perceptualmotor feedback to solve Aesop's fable tasks. PeerJ, 5, e3484. https://doi.org/10.7717/peerj.3484

Mulcahy, N. J., \& Call, J. (2006). How great apes perform on a modified trap-tube task. Animal Cognition, 9, 193199. https://doi.org/10.1007/s10071-006-0019-6

Nielsen, M. (2013). Young children's imitative and innovative behaviour on the floating object task. Infant and Child Development, 22, 44-52. https://doi.org/10.1002/icd.1765

O'Malley, R. C., \& McGrew, W. C. (2000). Oral tool use by captive orangutans (Pongo pygmaeus). Folia Primatologica, 71, 334-341. https://doi.org/10.1159/000021756

O'Leary, T., \& DeLong, C. M. (2016, April 16). An investigation of tool use abilities in young children (Homo sapiens) and orangutans (Pongo pygmaeus pygmaeus) [Poster presentation]. $23^{\text {nd }}$ Annual International Conference on Comparative Cognition, Melbourne, FL. https://www.comparativecognition.org/conferencespast.php

Renner, E., Abramo, A. M., Hambright, M. K., \& Phillips, K. A. (2017). Insightful problem solving and emulation in brown capuchin monkeys. Animal Cognition, 20, 531-536. https://doi.org/10.1007/s10071-017-1080-z

Sanz, C. M., Call, J., \& Boesch, C. (2013). Tool use in animals: Cognition and ecology. Cambridge University Press.

Schuster, S., Rossel, S., Schmidtmann, A., Jager, I., \& Poralla, J. (2004). Archer fish learn to compensate for complex optical distortions to determine the absolute size of their aerial prey. Current Biology, 14, 15651568. https://doi.org/10.1016/j.cub.2004.08.050

Seed, A., \& Bryne, R. (2010). Animal tool-use. Current Biology, 20, R1032-R1039. https://doi.org/10.1016/j.cub.2010.09.042

Shettleworth, S. J. (2012). Do animals have insight, and what is insight anyway? Canadian Journal of Experimental Psychology, 66, 217-226. https://doi.org/10.1037/a0030674

Shumaker, R., Walkup, K. R., \& Beck, B. B. (2011). Animal tool behavior: The use and manufacture of tools by animals. Johns Hopkins University Press.

St. Amant, R., \& Horton, T. E. (2008). Revisiting the definition of animal tool use. Animal Behaviour, 75, 11991208. https://doi.org/10.1016/j.anbehav.2007.09.028

Stanton, L., Davis, E., Johnson, S., Gilbert, A., \& Benson-Amram, S. (2017). Adaptation of the Aesop's fable paradigm for use with raccoons (Procyon lotor): Considerations for future application in non-avian and non-primate species. Animal Cognition, 20, 1147-1152. https://doi.org/10.1007/s10071-017-1129-z

Tennie, C., Call, J., \& Tomasello, M. (2010). Evidence for emulation in chimpanzees in social settings using the floating peanut task. PLoS One, 5, e10544. https://doi.org/10.1371/journal.pone.0010544

van Schaik C. P., Fox E. A., \& Sitompul A. F. (1996). Manufacture and use of tools in wild Sumatran orangutans. Naturwissenschaften, 83, 186-188. https://doi.org/10.1007/BF01143062

van Schaik, C. P., \& Knott, C. D. (2001). Geographic variation in tool use on Neesia fruits in orangutans. American Journal of Physical Anthropology, 114, 331-342. https://doi.org/10.1002/ajpa.1045

Volter, C. J., Rossano, F., \& Call, J. (2015). From exploitation to cooperation: Social tool use in orang-utan motheroffspring dyads. Animal Behaviour, 100, 126-134. https://dx.doi.org10.1016/j.anbehav.2014.11.025

Whiten, A., Horner, V., Litchfield, A. C., \& Marshall-Pescini, S. (2004). How do apes ape? Learning \& Behavior, 32, 36-52. https://doi.org/10.3758/BF03196005 